\title{
Large-scale and long-term variations in the zooplankton community of the Gullmar fjord, Sweden, in relation to advective processes
}

\author{
Odd Lindahl, Lars Hernroth
}

Kristineberg Marine Biological Station, S-450 34 Fiskebäckskil, Sweden

\begin{abstract}
Since 1978, long-term variations in zooplankton biomass have been studied in relation to the hydrography of the Gullmar fjord, west coast of Sweden. The effects of water exchange processes on the zooplankton community were given special attention. During each autumn extremely variable numbers of Calanus spp. (Stages CIV to $V$ ) were transported to the fjord by inflows of Skagerrak surface water Once inside the fjord, Calanus spp. descended into the deep water, but were more or less completely washed out again by the annual renewal of deep water during winter or spring. An anomaly in the zooplankton biomass which was observed in 1982-84 was caused by a more than 10 -fold increase in the abundance of Calanus. It was concluded that advective processes were the major factor regulating zooplankton biomass in the fjord.
\end{abstract}

\section{INTRODUCTION}

It is well known that changes in the dynamics of zooplankton communities in fjords are caused by both abiotic and biotic factors (Matthews \& Heimdal 1980). The abiotic factors can be roughly divided into environmental factors such as temperature and salinity, and physical factors such as advective flows and up- or downwelling. The biotic factors can simply be expressed as the extent of reproduction, growth, mortality and active migration.

The plankton community of the Gullmar fjord has been studied regularly since 1978. Relationships between hydrodynamic processes and changes in the pelagic community have been observed on several occasions. Conspicuous examples are the sudden appearance of the dinoflagellate Gyrodinium aureolum Hulburt in 1982 and 1983 (Lindahl 1983, 1986), distinct changes in the population structure of the shrimp Pandalus borealis Krøyer (Bergström, Kristineberg Marine Biological Station, pers. comm.) and sudden appearances of the scyphozoans Cyanea capillata (L.) and C. lamarckii (Peron \& Lesuer) (Gröndahl \& Hernroth 1987).

Short-term changes (in days) in the zooplankton community above the sill depth were found to be highly correlated with inflows of 'new' water to the fjord during March and April 1985 (Lindahl \& Perissinotto 1987).

This paper presents data which show that the plankton community in the more stable water masses below the sill depth is also significantly influenced by hydrodynamic processes and that due to the long residence times of the deep water, the effects of single water exchanges may be conspicuous for as long as 2 yr.

With the present knowledge on the effects of advective flows on the plankton community in mind, it is obvious that some of our conclusions in a previous paper on the plankton community of the fjord (Lindahl \& Hernroth 1983) were too hasty.

\section{MATERIAL AND METHODS}

Study area. The Gullmar fjord is situated on the Swedish west coast (Fig. 1). It has the properties typical of a fjord with a shallow sill of $42 \mathrm{~m}$ depth and a maximum depth of $120 \mathrm{~m}$ in the central part. The water body is always stratified, normally into 3 layers as follows: (1) water of salinity 18 to $30 \%$ at depths down to $20 \mathrm{~m}$; (2) water of salinity 30 to $34 \%$ at depths between 20; and $50 \mathrm{~m}$; (3) water of salinity $>34 \%$ at depths below $50 \mathrm{~m}$. 


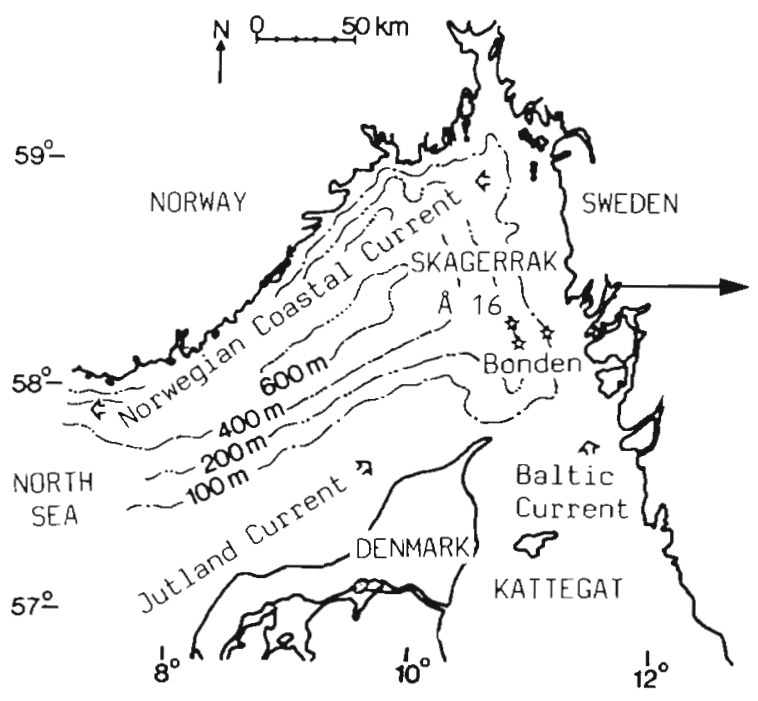

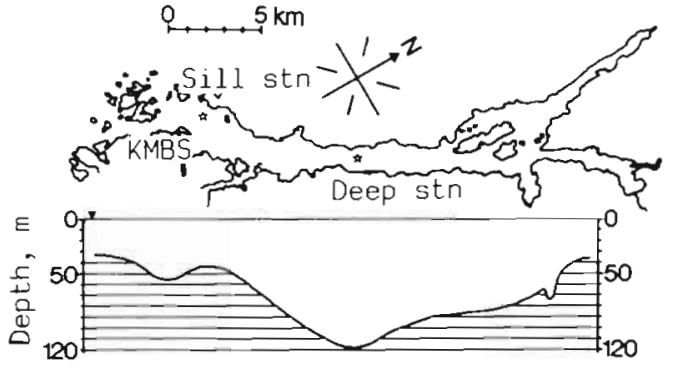

Fig. 1 The Skagerrak and Gullmar fjord showing sampling stations

Each of these water masses derives from separate sources. According to Svansson (1975), Baltic water of low salinity mixes with Kattegat and Skagerrak water of higher salinity, and is transported northwards along the coast by the Baltic Current (Fig. 1). Further, the high salinity water of North Sea-Skagerrak origin is transported towards the Swedish coast by the Jutland Current (Fig. 1). These 2 current systems meet in the eastern part of the Skagerrak and terminate as the Norwegian Coastal Current (Svansson 1975).

Since there is limited tidal exchange (tidal range = $0.25 \mathrm{~m}$; Svansson 1975) between the outer coastal waters and the fjord, inflowing water must be balanced against a simultaneous outflow of equal volume. The water flows across the sill are conditioned by both barotrophic and baroclinic currents, which are associated with variations in atmospheric pressure, winds, tides, internal waves and land runoff (Svansson 1975, 1984, Rydberg 1977, Shaffer \& Djurfeldt 1983). The water body above the sill depth has a mean residence time of less than 1 mo (Rydberg 1977). However, surface water of lower density above the pycnocline has a mean residence time of only $12 \mathrm{~d}$ (Hakkansson et al. 1984).

The residence time of the deep water in the fjord (below sill level) is approximately 8 to $10 \mathrm{mo}$, and renewal normally occurs during late winter (Svansson 1984). This means that the Gullmar fjord can be classified as a typical shallow-silled fjord (Gade \& Edwards 1980).

Sampling. All data were collected at a station in the deepest part of the fjord $(120 \mathrm{~m})$ about $10 \mathrm{~km}$ inside the sill. Altogether, samples were taken on 115 occasions, all during daylight, from 1978 to 1986.

Additional samples were taken on one occasion in 1984 outside the fjord at $100 \mathrm{~m}$ depth (Stn Bonden) and at $200 \mathrm{~m}$ depth (Stn $\AA 16$, Fig. 1). Extra samples were also collected outside the fjord in 1985 at 100 and $200 \mathrm{~m}$ depth (Bonden stations).

Temperature and salinity were measured at $5 \mathrm{~m}$ intervals from the surface to $30 \mathrm{~m}$, and then every $10 \mathrm{~m}$ down to the bottom. Until the middle of 1985 temperatures were measured with reversing thermometers (accuracy $\pm 0.05 \mathrm{C}^{\circ}$ ) and salinity was measured with laboratory salinometers (accuracy $\pm 0.05 \%$ ). During the last $18 \mathrm{mo}$ of the investigation a CTD-instrument (Type M. E. OTS 1500) with the same accuracies was used.

Oxygen was measured by a modified Winkle method (Carrit \& Carpenter 1966) in water samples collected with Knudsen water bottles.

Mesozooplankton samples 10.2 to $20 \mathrm{~mm}$, Sieburth et al. 1978) were always collected by vertical hauls using a standard UNESCO WP Il net with a mesh size of $200 \mu \mathrm{m}$. On some occasions sampling was extended to include fractionated vertical hauls with a WP II net with a mesh size of $90 \mu \mathrm{m}$. This was done in order to gain information on the vertical distribution of the fauna and to catch the smaller size fractions. The nets were towed at a speed of $0.5 \mathrm{~m} \mathrm{~s}^{-1}$.

All zooplankton samples were preserved in $4 \%$ formalin buffered with di-sodium tetraborate. Biomass determinations were performed by the displacement technique according to Dybern et al. (1976). Medusae, euphausids, chaetognaths and the polychaete Tomopteris helgolandica which all occasionally occurred in the samples were excluded since these organisms were not representatively caught by the net.

The most abundant mesozooplankters below sill level in the fjord are the calanoid copepods $\mathrm{Mi}$ crocalanus pusillus (G. O. Sars), Calanus finmarchicus 
(Gunnerus) and C. helgolandicus (Claus). The 2 species of Calanus have sympatric distributions over a large area of the North Atlantic and the adjoining North Sea (Williams \& Conway 1980, Hirche 1984). However, except for copepodite Stages CV and CVI, it is extremely difficult to separate the 2 species morphologically (Williams \& Conway 1980). Since this paper focuses mainly on the effects of advective processes on the plankton community rather than on the ecology of individual species, the 2 Calanus species are not separated here.

\section{RESULTS}

\section{Water exchange processes}

Above the sill depth the exchange of water was always a fairly continuous process, and consequently, it was generally not possible to identify single exchanges when the normal sampling frequency was used. However there were some periods and events during which the sampling frequency of the hydrographic measurements was increased and single water exchanges could be identified (Figs. 5 and 6).

During the entire investigation, the exchange of the deep water of the Gullmar fjord always took place during the period December to May, and in particular from January to March. The large exchanges extending all the way down to the bottom were always preceded by a number of partial exchanges beginning at the top of the stagnant layer and extending successively towards the bottom. These events were easily detected by studying changes in the vertical oxygen

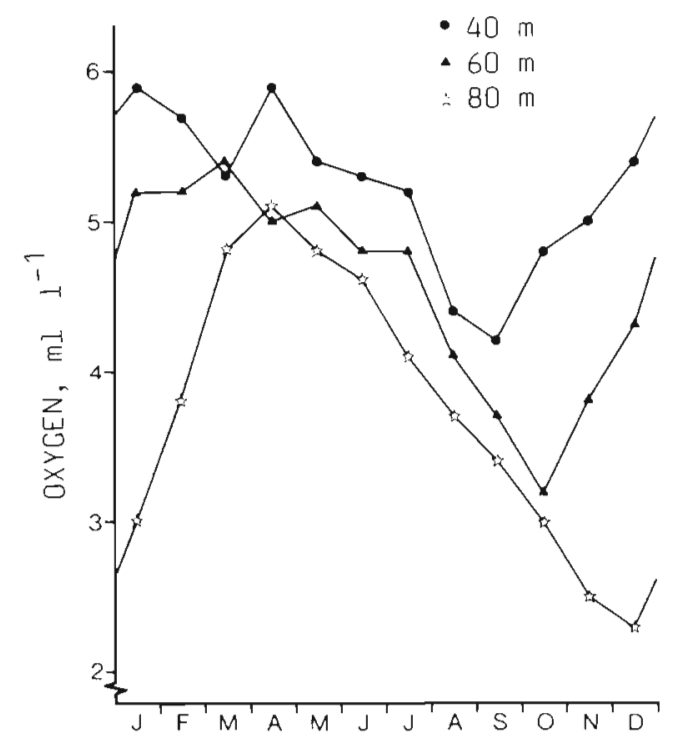

Fig. 2. Mean oxygen concentration ( $\mathrm{ml} \mathrm{l}^{-1}$ ) from 1978 to 1986 at 40,60 and $80 \mathrm{~m}$ depth in the Gullmar fjord distribution (Figs. 2 and 6), but could also be seen in the time series of temperature and salinity.

The exact history of each water exchange below the sill depth during the investigated period is not known. However, on many occasions the processes behind the renewal of the deep water of the Gullmar fjord were identified in the same way as those reviewed by Gade \& Edwards (1980). These processes consisted of easterly (longitudinal) winds which caused an outflow of surface water and thus forced heavier water to rise, or northerly longshore winds which caused coastal upwelling. In both cases renewal took place when the density of the elevated water outside the sill was greater than that of the water inside the sill.

However, in spring 1985 renewal of the deep water was preceded by different meteorological events which have not previously been observed to cause deep water renewal in the Gullmar fjord. After $2 \mathrm{wk}$ of northeasterly winds at the end of March, a renewal occurred after some days of strong westerly and northwesterly winds. The water entering the deep area of the fjord was identified as former Skagerrak surface water by its low temperature $\left(<4^{\circ} \mathrm{C}\right)$, the decrease in salinity and the sudden appearance of phytoplankton below the sill depth in the fjord.

\section{The zooplankton community}

Throughout the period of investigation, the pattern of seasonal variations in biomass was rather uniform (Fig. 3). However, during the years 1982-84, there was a conspicuous difference in biomass amplitude compared to the preceding and following periods.

In Fig. 3 the results from the biomass determinations are therefore divided into 3 periods: (1) monthly mean biomass values for 1978-81 (error bars = discrete maximum and minimum values); (2) discrete biomass values for 1982-84; and (3) monthly mean biomass values for 1985-86 (error bars as above).

\section{Seasonal variations in mesozooplankton biomass excluding the period 1982-84}

In January, February and March, the mesozooplankton biomass in the fjord was very small (ca $0.5 \mathrm{~g} \mathrm{~m}^{-2}$ dry wt; Table 1, Fig. 3). Virtually no copepods were found in the surface layer. Ciliates and barnacle nauplii were numerous (Hernroth 1983), but were not of importance for the total biomass. The main component of the biomass was the large calanoid copepod Calanus spp. (Stages CV and CVI), which was found in the deepest layer (60 to $120 \mathrm{~m}$ ).

During spring and summer the diversity and abun- 


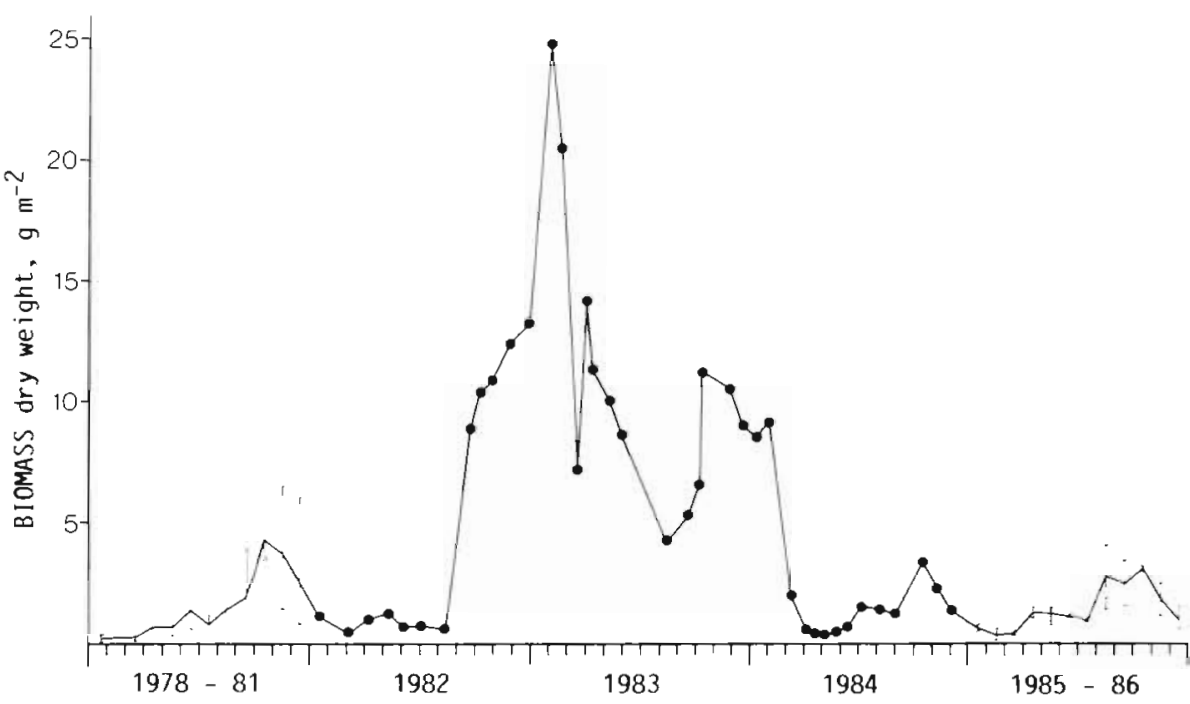

Fig. 3. Mesozooplankton biomass expressed as dry weight $\left(\mathrm{g} \mathrm{m}^{-2}\right.$ 120 to $0 \mathrm{~m}$ ) in the Gullmar fjord: monthly mean values for $1978-81$ and 1985-86 (error bars $=$ discrete maximum and minimum values and discrete values for 1982-84 dance of the mesozooplankton increased. In particular, the cyclopoid copepod Oithona similis (Claus) and the cladocerans Evadne nordmanni (Lovén) and Podon spp. were at times extremely abundant. However, due to the sharp decline in Calanus abundance during this period (Fig. 3), the biomass remained rather small (ca $1 \mathrm{~g} \mathrm{~m}^{-2}$ ).

A marked increase in zooplankton biomass occurred in the fjord during September and October of each year (Table 1, Fig. 3). The qualitative analyses of the samples showed that sudden appearances of Stages CIV and CV of Calanus spp. were alone responsible for the increases observed. During the autumn, the diversity and abundance of mesozooplankton were still considerable. The analyses of the fractionated net hauls showed that at this time of the year Calanus was only found in the deepest water layer (60 to $120 \mathrm{~m}$ ).

This vertical distribution of Calanus during the autumn was also reflected in samples collected at 2 stations outside the fjord in November 1985 (Bonden, 100 and $200 \mathrm{~m}$; Fig. 1). At both stations the major part of the Calanus population was found in the deepest haul ( 100 to $60 \mathrm{~m}$ and 200 to $100 \mathrm{~m}$ respectively).

At the end of each year, with the exception of 1982 , there was a gradual decrease in biomass (Fig. 3). This was caused by a gradual decrease in the diversity and abundance of the fauna occupying the layers above the sill level $(40 \mathrm{~m})$. Thus, by the end of the year, this part of the water column had almost no mesozooplankton. The Calanus population originating from the autumn immigration remained in the deep layer of the fjord together with older stages of the calanoid copepods Pseudocalanus elongatus (Boeck) and Microcalanus pusillus.

\section{Anomaly in zooplankton abundance in $1982-84$}

During the first 7 mo of 1982 , the patterns of biomass and species composition did not deviate from those observed in previous years. Throughout June, July and early August the total mesozooplankton biomass was less than $1 \mathrm{~g} \mathrm{~m}^{-2}$, and was composed of cladocerans, calanoid and cyclopoid copepods and meroplankton. Less than 1000 ind. $\mathrm{m}^{-2}$ of Calanus spp. (mainly Stages CIII and CIV) were found on 11 August. However, by 21 September a dramatic change had occurred. The total biomass had increased more than 10-fold (Fig. 3) and the number of Calanus had increased to 75000 ind. $\mathrm{m}^{-2}$ (Fig. 4). Of these, 73000 belonged to Stages CIV and $V$. Two increases in the salinity of the surface water in the fjord were observed during this period (Fig. 5). An analysis of the meteorological and hydrographical data revealed that no upwelling of deep water had occurred and that the 2 increases in salinity were due to inflows of Skagerrak water.

Throughout the autumn of 1982 the immigration to the fjord by Stages CIV and CV of Calanus continued (Fig. 4). These were rich in stored fat, and once in the fjord they descended to the deep layer (60 to $120 \mathrm{~m}$ )

Table 1 Monthly mean zooplankton biomass (dry wt, $\mathrm{g} \mathrm{m}^{-2}$ ) in the Gullmar fjord in the periods $1978-81$ and $1985-86$

\begin{tabular}{|lccccccccccccc}
\hline & Jan & Feb & Mar & Apr & May & Jun & Jul & Aug & Sep & Oct & Nov & Dec \\
\hline Biomass & 0.45 & 0.38 & 0.41 & 1.00 & 1.00 & 1.32 & 0.87 & 1.95 & 2.13 & 3.84 & 3.09 & 2.05 \\
\hline
\end{tabular}


Fig. 4. Calanus spp. Cumulative abundance of Stages CI to III, $\mathrm{CIV}$ and $\mathrm{V}$, and CVI (ind. $\mathrm{m}^{-2}$ ) in the Gullmar fjord during the anomaly from 1982 to 1984
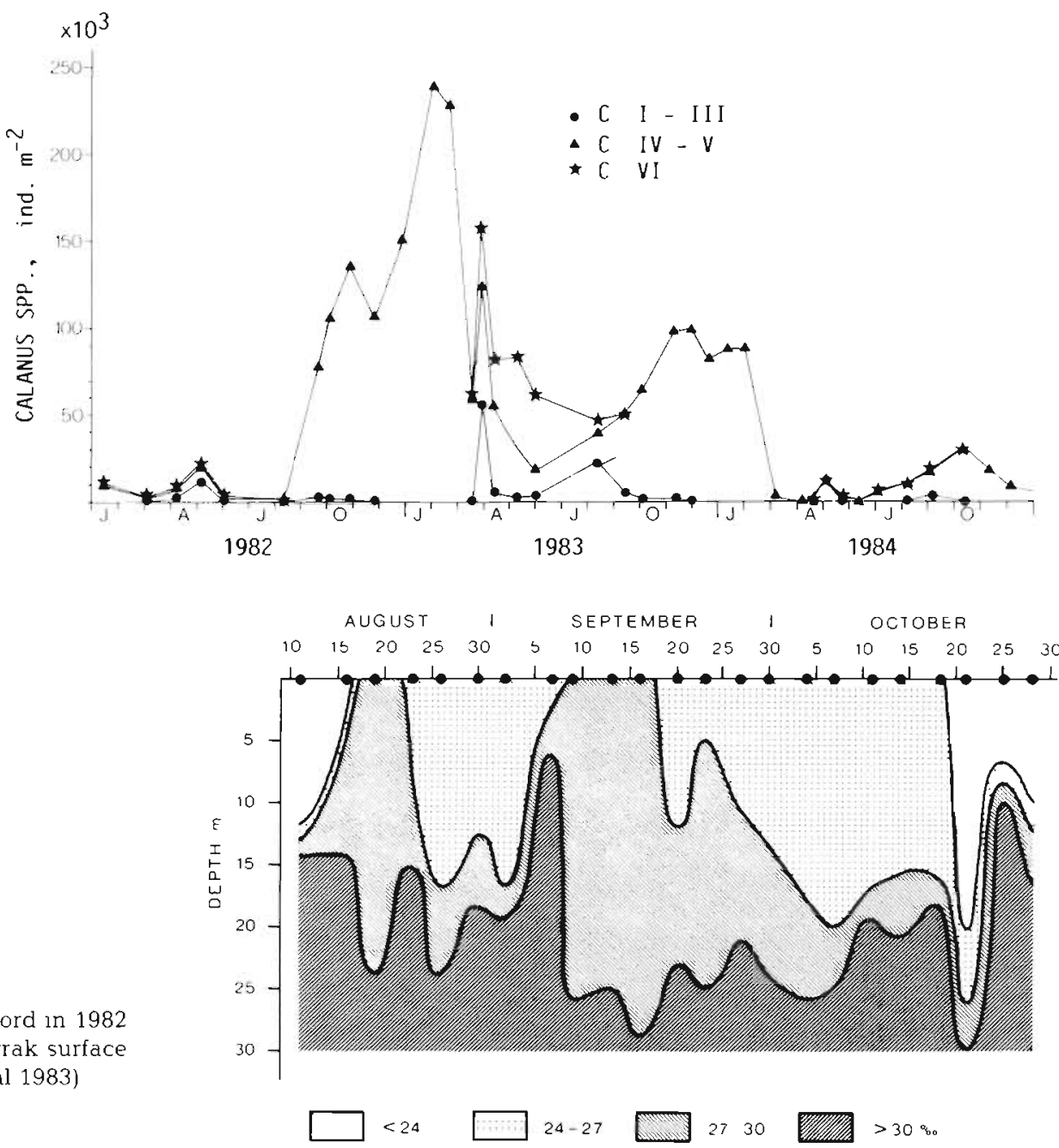

Fig. 5. Salinity (\%) in the Gullmar fjord in 1982 during a period of inflows of Skagerrak surface water. (Reproduced from Lindahl 1983) also the structure of the Calanus population. The period of total dominance by Stage $\mathrm{CV}$ was now replaced by a period when Stage $C V$, mature females and Stages CI to III were all abundant (Fig. 4). However, this period did not last very long and by mid-April

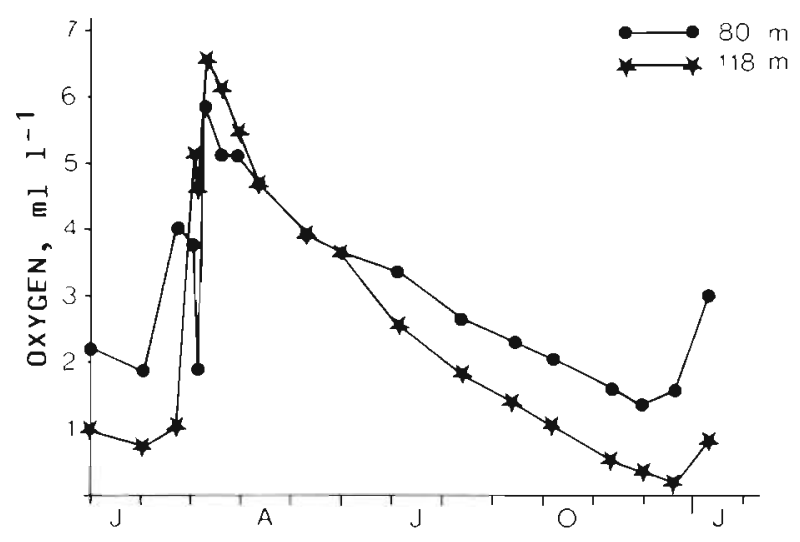

Fig 6. Oxygen concentration ( $\mathrm{ml}^{-1}$ ) dunng 1983 at 80 and
$118 \mathrm{~m}$ depth in the Gullmar fjord
Fig 6. Oxygen concentration ( $\mathrm{ml} \mathrm{l}^{-1}$ ) dunng 1983 at 80 and
$118 \mathrm{~m}$ depth in the Gullmar fjord mainly above the sill depth. These processes influenced not only the total biomass and abundance, but
This immigration caused an exceptional increase in both Calanus abundance and total biomass, so that by January 1983 there were 240000 ind. $\mathrm{m}^{-2}$ of Calanus stages CIV and $\mathrm{V}$ with a biomass of almost $25 \mathrm{~g} \mathrm{~m}^{-2}$ (Figs. 3 and 4 ). These are the highest values ever recorded in the fjord.

However, in February 1983 a new dramatic phase started. A partial renewal of the deep water (to $80 \mathrm{~m}$ depth), most obvious as an increase in oxygen from 2 to $4 \mathrm{ml}^{-1}$ (Fig. 6), started to reduce both the blomass and the abundance of Calanus. In March, there was a major renewal of the deep water in the fjord (Table 2, Fig. 6). This reduced the number of Calanus by $75 \%$ and the total biomass by $71 \%$. Despite the great reduction of the Calanus population due to the water renewal, the remaining stock was considerably larger than in prevlous years

Shortly after this main water renewal, there was a period in which several minor exchanges occurred, 
Table 2. Influence of deep-water renewals on the zooplankton biomass of the Gullmar fjord during 1979-86

\begin{tabular}{|c|c|c|}
\hline Sampling date & $\begin{array}{l}\text { Oxygen at } \\
118 \mathrm{~m}_{\left(\mathrm{ml}^{-1}\right)}\end{array}$ & $\begin{array}{c}\text { Biomass } \\
\text { ( } \mathrm{g} \mathrm{m}^{-2} \text { dry wt) }\end{array}$ \\
\hline 1979 & & \\
\hline Before renewal (19 Dec 1978) & 1.6 & 6.00 \\
\hline After renewal (5 Feb) & 4.1 & 1.10 \\
\hline 1980 & \multicolumn{2}{|c|}{ No data } \\
\hline \multicolumn{3}{|l|}{1981} \\
\hline Before renewal (2 Mar) & 1.3 & 0.55 \\
\hline After renewal $(10 \mathrm{Apr})$ & 4.5 & 0.80 \\
\hline Second renewal (12 May) & 5.9 & 1.10 \\
\hline \multicolumn{3}{|l|}{1982} \\
\hline Before renewal (23 Dec 1981) & 1.3 & 1.89 \\
\hline After renewal (15 Jan) & 4.6 & 1.17 \\
\hline Second renewal ( $4 \mathrm{Mar}$ ) & 6.1 & 0.45 \\
\hline \multicolumn{3}{|l|}{1983} \\
\hline Before renewal (22 Feb) & 1.1 & 20.38 \\
\hline After renewal (18 Mar) & 6.2 & 7.14 \\
\hline \multicolumn{3}{|l|}{1984} \\
\hline Before renewal (2 Feb) & 0.9 & 9.26 \\
\hline After renewal (7 Mar) & 6.2 & 2.08 \\
\hline \multicolumn{3}{|l|}{1985} \\
\hline Before renewal (14 Mar) & 1.6 & 0.49 \\
\hline After renewal (18 Apr) & 6.0 & 1.55 \\
\hline \multicolumn{3}{|l|}{1986} \\
\hline Before renewal (27 Jan) & 1.6 & 0.66 \\
\hline After renewal (27 Feb) & 6.1 & 0.15 \\
\hline
\end{tabular}

most of the younger stages of Calanus (CI to III) had disappeared.

The new deep water which entered in March remained in the fjord throughout 1983. In this stagnant water below the sill depth, it was possible to follow the development of the 'trapped' Calanus population for longer than 9 mo. As can be seen from Fig. 4, Stages $\mathrm{CIV}$ and $\mathrm{V}$ gradually developed into mature females during the spring. The relatively small number of Calanus nauplii found in the $90 \mu \mathrm{m}$ net samples at this time indicated that recruitment was limited. This was also illustrated by the low abundance of Stages CI to III during the summer (Fig. 4). The total number of Calanus slowly decreased throughout spring and early summer, with a subsequent drop in biomass (Fig. 3).

The pattern observed during late autumn in 1982 was repeated in September and October 1983. There was a very rapid increase in the abundance of Calanus Stages CIV and V (Fig. 4). There was a simultaneous decrease in the abundance of females and Stages $\mathrm{CI}$ to III, but the magnitude of the increase in the abundance of Stages CIV and V revealed that this was mainly due to a process of transport and not to recruitment from the resident population.

Throughout the autumn of 1983 , both the biomass and the abundance of Calanus remained at high levels (Figs. 3 and 4). In early 1984, just as in previous years, there was a major deep-water renewal in the fjord, with drastic effects on both the total biomass and the abundance of Calanus (Table 2). Unlike the situation following the renewal in 1983, this water exchange almost totally depleted the Calanus population, marking an end to the anomaly that had started 18 mo earlier with the extensive immigration of Calanus Stages CIV and $\mathrm{V}$.

In 1984 there was no repetition of the events observed in spring 1983, namely the development of Stage CV into mature females and the appearance of nauplii and Stages CI to III. Instead, during the remainder of 1984, the total biomass and the abundance of Calanus spp. followed a pattern similar to that observed prior to and following the $18 \mathrm{mo}$ of the anomaly (Figs. 3 and 4 ).

\section{Influence of the deep-water renewals on the zoo- plankton community}

Knowing that almost all mesozooplankters are concentrated in the deep water of the fjord during the winter, it is easy to understand that the winter renewals of deep-water were of fundamental importance to the fauna. In Table 2, the effects of the major winter-spring renewals are described in terms of the oxygen content of the deep water and the mesozooplankton biomass. These renewals were always preceded by extensive partial water exchanges down to 60 to $80 \mathrm{~m}$ (Figs. 2 and 6).

The analyses of the plankton samples which were taken before and after these events showed that a major part of the overwintering Calanus population had been washed out of the fjord in connection with the water renewals. The zooplankton abundance in the new water entering the fjord was extremely low. This

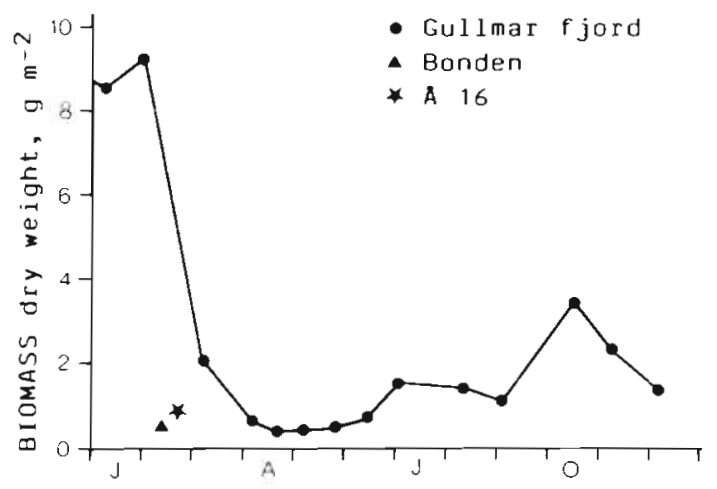

Fig. 7 Mesozooplankton biomass ( $\mathrm{g} \mathrm{m} \mathrm{m}^{-2}$ dry wt) during 1984 in the Gullmar fjord $(118 \mathrm{~m})$ and at Stns Bonden $(100 \mathrm{~m})$ and

$\AA 16(200 \mathrm{~m})$ before the deep water renewal in the fjord 
Table 3. Zooplankton biomass $\left(\mathrm{g} \mathrm{m}^{-2}\right)$ and numbers of Calanus spp. (ind. $\mathrm{m}^{-2}$ ) at Stns Gullmar fjord (depth $120 \mathrm{~m}$ ), Bonden (depth $100 \mathrm{~m}$ ), $\AA 16$ (depth $200 \mathrm{~m}$ ) and Sill area (depth $45 \mathrm{~m}$ ) in February 1984 (Fig. 1)

\begin{tabular}{|rlrcc|}
\hline Date & \multicolumn{1}{c}{ Station } & $\begin{array}{c}\text { Sampling } \\
\text { interval }\end{array}$ & $\begin{array}{c}\text { Biomass } \\
\left(\mathrm{g} \mathrm{m}^{-2}\right)\end{array}$ & $\begin{array}{c}\text { Calanus } \mathrm{spp} \\
\left.\text { (ind. } \mathrm{m}^{-2}\right)\end{array}$ \\
\hline $2 \mathrm{Feb}$ & Gullmar fjord & $120-0$ & 9.26 & 88000 \\
$9 \mathrm{Feb}$ & Bonden & $100-0$ & 0.36 & 1520 \\
$20 \mathrm{Feb}$ & A16 & $200-0$ & 0.93 & 4280 \\
$27 \mathrm{Feb}$ & Sill area & $45-0$ & - & $\sim 0$ \\
\hline
\end{tabular}

could be seen not only in the samples taken in the fjord following the water renewals but also in samples taken at the Bonden and $\AA 16$ stations outside the fjord prior to the exchange in 1984 (Table 3, Fig. 7).

In Table 4 the amount of renewed deep water is compared with the decrease in the biomass and abundance of Calanus for 1983 and 1984. The amount of exchanged water was calculated from the oxygen content of the water outside the sill measured shortly before the renewal and that of the water below the depth of $60 \mathrm{~m}$ in the fjord before and after the inflow. It must be pointed out that the plankton content of the inflowing water was not taken into consideration.

Table 4. Relation between the amount of renewed deep water and the decrease in biomass and abundance of Calanus spp. during 1983 and 1984

\begin{tabular}{|cccc|}
\hline Year & $\begin{array}{c}\text { Proportion of } \\
\text { deep water not } \\
\text { exchanged (\%) }\end{array}$ & $\begin{array}{c}\text { Remaining } \\
\text { biomass after } \\
\text { renewal (\%) }\end{array}$ & $\begin{array}{c}\text { Remaining } \\
\text { Calanus CIV-V } \\
\text { after renewal (\%) }\end{array}$ \\
\hline 1983 & 19 & 35 & 25 \\
1984 & 13 & 22 & 3 \\
\hline
\end{tabular}

\section{DISCUSSION}

The $9 \mathrm{yr}$ of continuous monitoring in the Gullmar fjord have shown that there is a year to year consistency in the composition of the zooplankton community and in the dynamics of the hydrography. The seasonal variations in species composition, biomass and water exchange can be said to follow a predictable pattern. However, the magnitude and timing of these variations differ greatly between years. Advective processes seem to be the main regulator, while environmental conditions such as temperature, salinity, oxygen and food supply are less important. The special characteristics of the fjord, which is a semi-enclosed area with a sill which prevents free exchange of the water body below the sill depth with the adjoining coastal waters, reinforce this dependence on advection.
The first 4 yr of the present investigation were partly evaluated by Lindahl \& Hernroth (1983). In that paper we concluded that the mesozooplankton biomass in the Gullmar fjord did not increase appreciably during autumn until the end of the seasonal occurrence of the scyphomedusae Aurelia aurita and Cyanea spp. It was supposed that predation by these medusae regulated the whole pelagic system during summer. However, we now know that the observed increase in biomass during autumn was due to the downward migration and accumulation into the deep water of the fjord of Stages IV and V of Calanus spp. It is still probable that the medusae had a regulating effect, but this was obviously of less importance than first believed.

Furthermore, we concluded that the decreasing trend in zooplankton biomass that was observed from 1978 to 1981 could have been caused by large-scale hydrometeorological changes in the North Atlantic Region, as suggested by Colebrook (1978), Colebrook \& Coombs (1978) and Reid (1978). However, during 1982-84 the downward trend did not continue in the Gullmar fjord, as described in the present paper, and no trend can be identified during the whole period of investigation.

Unfortunately, only single samples of the zooplankton community were taken on each sampling occasion. This is insufficient from a statistical point of view. However, the authors are convinced that statistically more appropriate sampling would not have changed the conclusions of this investigation in any decisive way.

\section{Significance of the busaviour of Calanus for its abundance and biomass in the Gullmar fjord}

A common feature of the entire investigation was the close link between the abundance of Calanus spp. and the total mesozooplankton biomass. This is due not only to the abundance of Calanus but also to a large extent to the size of this species in comparison with most other regularly appearing mesozooplankters.

Our results show that Calanus is not a permanent resident of the fjord. There were several occasions when only a few or no individuals were found. It is also obvious that Calanus does not reproduce successfully in the fjord, and in some years there are no signs of reproduction at all. During the lengthy stagnation of the deep water in 1983, it was possible to follow the development of the 'trapped' population. From these studies we conclude that Calanus produces at the most one generation per year in the fjord. This is in agreement with results from some Norwegian fjords (Tande 1982, Lie et al. 1983).

In the Gullmar fjord, the Stage $V$ copepodites moult 
into adults during the period February to June, and Stages CI to III of the new generation are first found in March. In contrast to the overwintering population, these younger stages are mainly found at depths above the sill level. The conspicuous decrease in the abundance of Calanus in spring and summer is probably connected with their position in the water-column. It has been shown by Lindahl \& Perissinotto (1987) that the plankton community above the sill depth is subject to rapid changes due to the frequent water exchanges in the surface layers. The offspring of the overwintering population may thus be 'washed out' of the fjord. As the mortality rate is particularly high among the younger stages of Calanus (Aksnes \& Magnesen 1979), there are several reasons why recruitment is so limited in the fjord during spring.

In Calanus, the overwintering phase starts as early as the beginning of summer with a gradual descent by the older stages to deeper layers (Aksnes \& Magnesen 1979, Williams \& Lindley 1980, Tande 1982, Tande \& Slagstad 1982, Hirche 1983). In the Gullmar fjord, this phase is not particularly pronounced, due to the low abundance of Calanus during summer. However, this pattern of descent into deeper layers is of fundamental importance for the zooplankton community of the fjord during the autumn. As these copepods enter the fjord, they descend towards the deeper layers below the sill level, and remain trapped in this stable water mass throughout the autumn until a new deep-water renewal takes place. The Calanus population is restricted to the deep layer $(60$ to $120 \mathrm{~m}$ ) throughout the autumn, but it totally dominates the overall mesozooplankton biomass.

According to Aksnes \& Magnesen (1979) the mortality of the overwintering stages (CIV to V) of Calanus is low and the reduction in individual weight is only of significance from December to March (Tande 1982). However, none of these factors have such a pronounced effect on the future development of the Calanus population and the mesozooplankton biomass in the fjord as do the time and extent of the renewal of deep water each winter.

Williams \& Lindley (1980) and Colebrook (1985) suggest that the success and strength of the overwintering Calanus population determines the eventual strength of the developing spring cohorts. This is also very evident in our investigation. In 1982 and 1984, virtually the whole overwintering population was washed out of the fjord. In 1983 on the other hand, a substantial part of the huge 1982 population remained, despite a major deep-water renewal during the winter, and successfully produced a spring cohort.

We have no explanation for the anomaly in the abundance of Calanus during 1982-84. Unfortunately, no sampling seems to have been carried out in the
Skagerrak during the period. Consequently, there are no data with which the increase in the abundance of Calanus in the Gullmar fjord can be compared. The origin of the Calanus population during the anomaly will thus probably remain unknown.

\section{Advective processes as a regulator of mesozooplank- ton biomass in the Gullmar fjord}

The origin of the different water masses in the Gullmar fjord is of great importance for the occurrence of different plankton species. Water above the sill depth in the fjord may originate from the Kattegat, the Skagerrak or even the North Sea. On some occasions it may have been transported from the deeper areas of the coast by coastal upwelling.

The influence of the variable hydrographic conditions above the sill on the zooplankton community has been investigated by Lindahl \& Perissinotto (1987). They found considerable differences in species composition and abundance between sampling occasions which were 2 to $3 \mathrm{~d}$ apart. They concluded that these differences were mainly due to the patchy horizontal distribution of the zooplankton in connection with water exchanges.

A typical example of the effect of surface-water advections was the sudden appearance each autumn of copepodite Stages IV and V of Calanus (Fig. 4). Our results have shown that this immigration occurred during periods of surface water influx from the Skagerrak (Fig. 5) when dinoflagellates (Lindahl 1983, 1986) and certain scyphozoans were also brought to the fjord (Gröndahl \& Hernroth 1987).

Another example was the disappearance in April 1983 of the CI to III stages of Calanus, which had been brought into the fjord in March. This was probably due to seaward transport of surface water out of the fjord. We observed a similar situation at the end of April 1978 when there was a pronounced decrease in the abundance of fish eggs and larvae in the Gullmar fjord in connection with easterly winds (Andersson et al. 1979).

The lack of water exchange below the sill depth during 8 to 10 mo of the year, the probability that the incoming water is of deep-water origin and the fact that the renewals almost always occur during winter, make it possible to predict that the annual renewals of deep water will usually reduce the mesozooplankton biomass in the fjord considerably. This situation implies that the resident plankton will always be washed out to a certain degree during the renewals, and that there will be a general lack of zooplankton in the incoming deep water

However, deviations from the above pattern were also observed. In 1981 and 1985 the biomass increased 
during the period of deep-water renewal. During these years, it was found that the small Calanus population which had been resident during winter decreased in abundance, as in other years. The increase in biomass was instead caused by surface-dwelling species such as Acartia longiremis (Lilljeborg), Temora longicornis (Müller) and Centropages hamatus (Lilljeborg). Two factors seem to be of importance: there was a small overwintering population of Calanus, and the renewal occurred in spring, when both the diversity and abundance of surface-dwelling species had increased. This explanation is supported by the results from 1986 , when the usual decrease in biomass was found, although the Calanus population was small before the renewal of deep-water. In 1986, the renewal occurred in February and consequently there had not yet been any increase in the abundance of surface-dwelling zooplankters.

There can thus be considerable variability in the transport of the zooplankton community in and out of the fjord. If this variability were to be overlooked, it could certainly lead to erroneous conclusions. Just imagine what kind of conclusions could have been reached if this investigation had started or ended during the anomaly in 1982-84, when there was a 10-fold increase in biomass, without knowledge of the immigration by Calanus! It is obvious that there are no 'normal' years.

\section{Comparisons with other studies on advective transport}

The effects of exchanges of water-masses in fjords on zooplankton communities have been observed by many authors. Stone (1980) found that an intrusion of offshore water in Knight Inlet (British Columbia, Canada) in May 1975 introduced a number of copepod species which had previously not been present in the area. Most of these immigrants declined rapidly in abundance while some were still found a few months later. However, a year later none of the new species could be found and Stone concluded that the event was probably unusual.

Matthews \& Heimdal (1980) demonstrated the openended nature of fjord communities by giving several examples. For instance, much of the Calanus occurrence in Korsfjord (Norway) can only be explained by advective processes. Another example from Korsfjord is the changing biomass of the euphausid Meganyctiphanes norvegica (M. Sars), which fluctuated in a manner rather similar to that of Calanus in the Gullmar fjord during the anomaly in 1982-84.

Lie et al. (1983) stated that Calanus finmarchicus was introduced into the Lindåspollene, Norway, by advec- tive transport from surrounding fjord systems, but it disappeared from the zooplankton community during summer. Hirche $(1983,1984)$ pointed out the importance of water transport for the immigration of Calanus spp. to the Gullmar fjord. However, there was not sufficient hydrographical data to confirm the hypothesis of advection.

\section{Origin of Calanus spp. found in the Gullmar fjord}

On the basis of the present data, it is not possible to say from where the Gullmar fjord populations of Calanus finmarchicus and C. helgolandicus are recruited. According to Matthews (1969), C. helgolandicus is considered a warm temperate and $C$. finmarchicus a cold temperate form. Rees (1949) believes that C. finmarchicus spreads southwards into the North Sea from the northwest and Matthews (1969) found a main center of abundance of $C$. helgolandicus within the Plankton Recorder Survey area to the east and southeast of the British Isles.

According to Rees (1949), one possible source of overwintering Calanus is the deep basin of the central Skagerrak (600 m; Fig. 1). Reports by Eriksson (1973) and Richardson (1985) of Calanus females with eggs and nauplii in the Kattegat and north of Denmark in early spring could be an indication of an overwintering stock. On the other hand, the absence of regular spring immigration to the fjord in connection with the transport of surface water speaks against a theory of the Skagerrak being an overwintering area.

Until further data on the origin of the Calanus populations in the fjord are available, we can merely speculate that the 2 Calanus species are transported to the fjord from the North Sea area. Based on the current speeds reported by Svansson (1975), the investigations on the distribution of the radionuclide ${ }^{137} \mathrm{Cs}$ from the strait of Dover to Skagerrak (Kautsky 1973, Aarkrog et al. 1983) it is theoretically possible that the populations entering the fjord each autumn may have a far distant origin with a drift up to 5 mo. Hirche (1984) reached a similar conclusion about the source of $C$. helgolandicus appearing in the Gullmar fjord during autumn. The possibility of long-distant transport of plankton from the southern North Sea to the Skagerrak area within 5 mo is also supported by the model of Hainbucher et al. (1987) on the transport of conservative tracers in the North Sea.

The increase in abundance of Calanus spp. during August and September 1982 and October 1983 occurred simultaneously with the appearance of the dinoflagellate Gyrodinium aureolum which was recorded by Lindahl (1983, 1986). The simultaneous increase and appearance were due to the fact that both species 
were brought to the fjord by the same water-mass. It is tempting to speculate that $G$. aureolum and Calanus originate from the same area. G. aureolum is probably not a permanently occurring species in the Skagerrak, but it is abundant most years during late spring and summer in offshore fronts between different water masses around the British Isles (Pingree et al. 1975, 1976, Tangen 1977, Holligan 1979, Parker et al. 1982). The southern North Sea and English Channel are thus areas in which both Calanus spp. and $G$. aureolum occur regularly. It must be pointed out however, that if the 3 species occur in the same water mass when they reach the fjord, this may also be the result of mixing on the way in the North Sea or the Skagerrak area.

Acknowledgements. This investigation was financed by grants from the Swedish Environmental Protection Agency, the County Board of Gothenburg and Bohuslän and the Swedish Natural Research Council. These contributions are gratefully acknowledged. We thank Prof. J. O. Stromberg and the staff of the Kristineberg Marine Biological Station for providing excellent working facilities. We are also grateful to $J$. Nelson for drawing the figures and to $\mathrm{C}$. Hill for the linguistic corrections.

\section{LITERATURE CITED}

Aksnes, D. L., Magnesen, T. (1979). Distribution, development, and production of Calanus finmarchicus (Gunnerus) in Lindåspollene, western Norway, 1979. Sarsia 68: 195-208

Aarkrog, A., Hansen. H., Lippert, J. (1983). Fall out nuclides in the abiotic environment. Environmental radioactivity in Denmark in 1982. Risø-R-487

Andersson, J., Hernroth, L., Lindahl, O. (1979). Västkustprojektet - Pelagialdel I. Forskningsrapport 1978, Kristinebergs Marinbiologiska Station (mimeo; Swedish)

Carrit, D. E., Carpenter, J. H. (1966). Comparisons and evaluation of currently employed modifications of the Winkler method for determining dissolved oxygen in sea water; a NASCO report. J. mar. Res. 24 (3): 286-318

Colebrook, J. M. (1978). Changes in the zooplankton of the North Sea 1948-1973. Rapp. P.-v. Réun. int. Explor Mer 172: $390-396$

Colebrook, J. M. (1985). Continuous plankton records: overwintering and annual fluctuations in the abundance of zooplankton. Mar Biol. 84: 261-265

Colebrook, J. M., Coombs, S. H. (1978). Continuous plankton records: a change in the plankton of the southern North Sea between 1970 and 1972. Mar. Biol. 45: 209-213

Dybern, B. I., Ackefors, H., Elmgren, R. (1976). Recommendations on methods for marine biological studies in the Baltic Sea. Baltic Marine Biologists, Publ. No. 1: 1-98

Eriksson, S. (1973). The biology of marine planktonic Copepoda on the west coast of Sweden. Zoon 1: 37-68

Gade, H. G., Edwards, A. (1980). Deep-water renewal in fjords. In: Freeland, H. J., Farmer, D. M., Levings, C. D. (eds.) Fjord oceanography. Plenum Press, New York, p. 453-490

GröndahI, F., Hernroth, L. (1987). Release and growth of Cyanea capillata (L.) ephyrae in the Gullmar Fjord, western Sweden. J exp. mar Biol. Ecol. 106: 91-101
Håkansson, L., Kulinski, I., Kvarnäs, H. (1984). Water dynamics and bottom dynamics in Swedish coastal waters. Swedish Envir. Prot. Bd PM 1905 (Swedish, English summary)

Hainbucher, D., Pohlmann, T., Backhaus, J. O. (1987). Transports of conservative passive tracers in the North Sea: first results of a circulation and transport model. Cont. Shelf Res. 7 (10): 1161-1179

Hernroth, L. (1983). Marine pelagic rotifers and tintinnids important trophic links in the spring plankton community of the Gullmar fjord, Sweden. J. Plankton Res. 5: 835-845

Hirche, H. J. (1983). Overwintering of Calanus finmarchicus and Calanus helgolandicus. Mar. Ecol. Prog. Ser. 11: 281-290

Hirche, H. J. (1984). Seasonal distribution of Calanus finmarchicus and $C$. helgolandicus in a Swedish fjord. Crustaceana Suppl. 7: 233-241

Holligan, P. M. (1979). Dinoflagellate blooms associated with tidal fronts around the British Isles. In: Taylor, D. L., Seliger, H. H. (ed.) Toxic dinoflagellate blooms. Elsevier/ North-Holland, New York, p. 249-256

Kautsky, H. (1973). The distribution of the radio nuclide caesium 137 as an indicator for North Sea water mass transport. Dt. hydrogr. Z. 26: 241-246

Lie, U., Magnesen, T., Tunberg, B., Aksnes, D. (1983). Preliminary studies on the vertical distribution of size-fractions in the zooplankton community in Lindasspollene, western Norway. Sarsia 68: 65-80

Lindahl, O. (1983). On the development of a Gyrodinium aureolum occurrence on the Swedish west coast in 1982. Mar. Biol. 77: 143-150

Lindahl, O. (1986). Offshore growth of Gyrodinium aureolum (Dinophyceae) - the cause of coastal blooms in the Skagerrak area? Sarsia 71: 27-33

Lindahl, O., Hernroth, L. (1983). Phyto-zooplankton community in coastal waters of western Sweden - an ecosystem off balance? Mar. Ecol. Prog. Ser. 10: 119-126

Lindahl, O., Perissinotto, R. (1987). Short-term variations in the zooplankton community related to water exchange processes in the Gullmar fjord, Sweden. J. Plankton Res. 9: $1113-1132$

Matthews, J. B. L. (1969). Continuous plankton records: the geographical and seasonal distribution of Calanus finmarchicus s. 1. in the North Atlantic. Bull. mar. Ecol. 6: 251-273

Matthews, J. B. L., Heimdal, B. R. (1980). Pelagic productivity and food chains in fjord systems. In: Freeland, H. J., Farmer, D. M., Levings, C. D. (ed.) Fjord oceanography Plenum Press, New York, p. 377-398

Parker, M., Dunne, T., McArdle, J. (1982). Exceptional marine blooms in Irish coastal waters. Coun. Meet. int. Coun Explor. Sea/L: 44 (mimeo)

Pingree, R. D., Holligan, P. M., Mardell, G. T., Head, R. N (1976). The influence of physical stability on spring, summer and autumn phytoplankton blooms in the Celtic Sea J. mar. Biol. Ass. U.K. 56: 845-873

Pingree, R. D., Pugh, P. R., Holligan, P. M., Forster, G. R (1975). Summer phytoplankton blooms and red tides along tidal fronts in the approaches to the English Channel. Nature, Lond. 258: 672-677

Rees, C. B. (1949). Continuous plankton records: the distribution of Calanus finmarchicus and its two forms in the North Sea, 1938-1939. Hull Bull. mar. Ecol. 2: 215-275

Reid, P. C. (1978). Continuous plankton records: large-scale changes in the abundance of phytoplankton in the North Sea from 1958-1973. Rapp. P.-v. Reun. Cons. int. Explor Mer 172: 384-389

Richardson, K. (1985). Plankton distribution and activity in the 
North Sea/Skagerrak-Kattegat frontal area in April 1984. Mar. Ecol. Prog. Ser 26: 233-244

Rydberg. L. (1977). Circulation in the Gullmaren - a sill fjord with externally maintained stratification. Inst. of Oceanography, Univ. of Gothenburg, Report No. 23 (mimeo)

Shaffer, G., Djurfeldt, L. (1983). On the low-frequency fluctuations in the eastern Skagerrak and in the Gullmaren. J. phys. Oceanogr. 13: 1321-1340

Sieburth, J. McN., Smetacek, V., Lenz, J. (1978). Pelagic ecosystem structure: heterotrophic compartments of the plankton and their relationship to plankton size fractions. Limnol. Oceanogr 23: 1256-1263

Stone, D. P. (1980). The distribution of zooplankton communities in a glacial run-off fjord and exchanges with the open sea. In: Freeland, H. J., Farmer, D. M., Levings, C. D. (eds.) Fjord oceanography. Plenum Press, New York, p. $291-297$

Svansson, A. (1975). Physical and chemical oceanography of the Skagerrak and the Kattegat. Fish. Bd Sweden, Inst. of Mar. Res. Report No. 1: 1-88

Svansson, A. (1984). Hydrography of the Gullmar fjord. Fish. Bd Sweden, Inst. of Hydr. Res. Series No. 23 (mimeo)
Tande, K. S. (1982). Ecological investigations on the zooplankton community of Balsfjorden, northern Norway: generation cycles, and variations in body weight and body content of carbon and nitrogen related to overwintering and reproduction in the copepod Calanus finmarchicus (Gunnerus). J. exp. mar Biol. Ecol. 62: 129-142

Tande, K. S., Slagstad, D. (1982). Ecological investigation on the zooplankton community of Balsfjorden, northern Norway. Seasonal and short-time variations in enzyme activity in copepodite stage $V$ and VI males and females of Calanus finmarchicus Gunnerus. Sarsia 67: 63-68

Tangen, K. (1977). Blooms of Gyrodinium aureolum (Dinophyceae) in North European waters, accompanied by mortality in marine organisms. Sarsia 63: 123-133

Williams, R., Conway, D. V. P. (1980). Vertical distributions of Calanus finmarchicus and $C$. helgolandicus (Crustacea: Copepoda). Mar. Biol. 60: 57-61

Williams, R., Lindley, J. A. (1980). Plankton of the Fladen Ground during FLEX 76 III. Vertical distribution, population dynamics and production of Calanus finmarchicus (Crustacea: Copepoda). Mar. Biol. 60: 47-56

This article was submitted to the editor; it was accepted for printing on December 14, 1987 